\title{
Pagar bem os profissionais da EB Construindo o sim e o como
}

\author{
João Antonio Cabral de Monlevade*
}

\begin{abstract}
RESUMO: $\mathrm{O}$ artigo trata do piso salarial dos profissionais e do mecanismo do "Custo-Aluno-Qualidade" (CAQ), ambos presentes em nossas leis, especialmente no Plano Nacional de Educação (PNE), a duras penas aprovados em 2014, e fala sobre a capacidade de financiamento do ensino público pelo Estado brasileiro.
\end{abstract}

Palavras-chave: Piso salarial profissional. Custo-Aluno-Qualidade. Financiamento do ensino.

\section{A questão}

$\mathrm{M}$

uito imposto já foi pago, muita greve já foi feita, muita tinta já se derramou sobre estes dois fatos persistentes no Brasil: professores são mal pagos e educação não tem qualidade. Que dizer então dos funcionários das escolas, escravos até 1888 e ameaçados pela terceirização em 2016? Trabalhadores de terceira categoria...

Ninguém provou que haja correlação perfeita entre baixo salário e baixa aprendizagem, mesmo porque educação, bem como ato de pai e mãe, é tão gratuita... E, como fato social, é muito complexa. Manoel da Nóbrega e São José de Anchieta nem tinham "honorários", como os outros servidores de Tomé de Souza e de Mem de Sá. E ninguém duvida da qualidade dos colégios jesuíticos. Mas os baixos salários, que levaram ao trabalho precário desde 1772 nas Aulas Régias e ao duplo emprego desde 1934, são fatos que se instalaram nas escolas e corroeram a aprendizagem dos estudantes nos 250 anos de assalariamento dos professores.

* Doutor em Educação. Professor aposentado da Universidade Federal de Mato Grosso (UFMT). Foi diretor da Confederação Nacional dos Trabalhadores em Educação (CNTE) (1987/1991) e atualmente é consultor legislativo do Senado Federal. Brasília/DF - Brasil. E-mail: <monlevad@senado.gov.br>. 
Se foi assim sempre - digamos, de 1772 para cá, de quando datam as primeiras lamúrias -, não seria uma "sina" de nossa sociedade brasileira o remunerar mal seus profissionais da educação básica? Pagar bem, principalmente agora, quando há crise de caixa e a educação básica virou produto de consumo das massas, com valor aparentado aos das farinhas e bananas, não seria missão impossível?

Ressalve-se uma "antiquestão": os mestres das universidades federais e de algumas estaduais vivem em bairros de classe média, "quase alta", por merecimento, mas, reconheçamos, por obra e graça de salários de igual valor aos dos colegas canadenses e suecos, desproporcionais às rendas per capita de seus países. O que lá é conquista histórica da maioria dos servidores públicos, aqui é seguramente privilégio.

Neste artigo, partindo das pegadas da história, vamos enfrentar a questão por meio do exame de dois constructos recentes: o piso salarial dos profissionais e o mecanismo do "Custo-Aluno-Qualidade" (CAQ), ambos presentes em nossas leis, especialmente no Plano Nacional de Educação (PNE), que a duras penas aprovamos em 2014 e tentamos cumprir.

\section{Dando um sentido à história do financiamento}

Parto de um princípio que não é unanimidade: o de que a história não só propicia lições, como também é campo de inserção e de compromisso em nossas ações pessoais e sociais. Construímos a história e, para isso, devemos conhecer seus passos.

Por exemplo: a educação escolar, no Brasil, como fato social e político, seguiu as seguintes fases: a da "não escola" (1500-1550); a da escola elitista, tanto a jesuítica quanto a pombalina (1550-1827); a da escola seletiva (1827-1988); e a da escola democrática. Esta é a lição. Lição que tento seguir, como professor e funcionário, na luta por construir a democracia nas escolas públicas para a maioria do povo brasileiro.

Há mais lições na história da educação. O propalado "dualismo educacional" também evoluiu em três períodos recentes: de 1834 a 1910, entre os que eram matriculados e os que estavam fora das escolas, fossem elas públicas ou privadas; de 1910 a 1961, entre os que estavam em escolas com itinerário propedêutico, destinados a chegar ao ensino superior, e os que se matriculavam em escolas profissionais, com terminalidade "antecipada" para garantir a subsistência no mercado de trabalho; de 1961 para cá, entre os que, na educação básica, são matriculados em escolas privadas para garantir acesso aos cursos superiores de alta concorrência (na maioria, públicos) e os que frequentam escolas públicas de decrescente qualidade, na educação básica, transferindo-se depois para cursos superiores em faculdades privadas.

Embora essas categorias da história da educação escolar se expliquem melhor por análises de estrutura de classes e por variáveis de apropriação de renda pelas famílias 
brasileiras, uma visão da evolução do financiamento da educação escolar é muito didática para reconhecê-las; e, numa linha propositiva, para superá-las.

Aqui vão quatro exemplos, que extraio de minha tese de doutoramento na Unicamp: Valorização Salarial dos Professores da Educação Básica Pública.

A surpreendente qualidade das escolas jesuíticas foi possível não pela ínfima receita da redízima a elas destinada pelos reis de Portugal. A abundância de insumos, que qualificaram seus 17 colégios e mais de 200 escolas de primeiras letras, adveio de oficinas e fazendas, onde escravos e religiosos "coadjutores" labutavam na inserção de indígenas catequizados na tecnologia europeia e na criação de milhares de cabeças de gado - o "petróleo" da economia colonial. Para a educação escolar elitista não faltaram recursos financeiros - ao contrário, sobraram, a ponto de propiciar sua própria ruina com o confisco ordenado pelo Marquês de Pombal em 1758.

O segundo exemplo se refere ao financiamento das Aulas Régias, criação "genial" do mesmo Primeiro-Ministro português. A Coroa, pela nomeação dos mestres, exigia sua fidelidade política e ideológica à Metrópole. Pela renda do tributo municipal chamado "subsídio literário", cobrado do abate dos bovinos nos açougues e da fabricação de aguardente, vinho e vinagre, ficava livre de qualquer ônus financeiro, em especial da folha de pagamentos. A pequena receita limitava ao mesmo tempo a expansão da oferta de vagas e a valorização dos "honorários" dos educadores, obrigando-os a ter a docência como segundo emprego. Essa desvalorização, de tão extorsiva, ecoou nos debates de nossa primeira Constituinte, de junho de 1822 até 1824.

O terceiro exemplo é o mais recente, que responde pela passagem do caráter limitado da oferta seletiva para a democrática. Desde 1834, pelo Ato Adicional à Constituição do Império, as despesas com a educação escolar (concentradas sempre no pagamento de pessoal) são oriundas dos impostos. Principalmente do tributo então criado sobre o consumo e que deu origem ao ICM, hoje Imposto sobre a Circulação de Mercadorias e Serviços (ICMS). Ora, com a urbanização e o adensamento populacional, o ICM e outros impostos, que durante 100 anos sustentaram a expansão das matrículas nos cursos primários e secundários, tornaram-se insuficientes e disputados por outras políticas públicas. A solução foi instituir um percentual mínimo de sua receita vinculado à Manutenção e Desenvolvimento do Ensino Público (MDE). Na Constituição de 1934, pelo art. 156, se fixaram os três mínimos: 10\% dos impostos federais e municipais e 20\% dos estaduais. De lá até 1988, com a última Constituição, por seu artigo 212, os mínimos evoluíram para 18\%, 25\% e 25\%, respectivamente. A Lei no 9.394, de 20 de dezembro de 1996 (Lei de Diretrizes e Bases da Educação - LDB), em seu artigo 69, não somente acresceu ao preceito legal nacional que as constituições estaduais e as leis orgânicas municipais poderiam aumentar esses mínimos vinculados à MDE, como também obrigou a que os entes federados repassassem de dez em dez dias suas receitas de MDE “aos órgãos responsáveis pela educação". 
Em outras palavras: induziu para mais as receitas para a educação, do que resultou que dez estados e centenas de municípios ultrapassassem os 25\%. Sem dúvida, a evolução positiva do financiamento possibilitou a passagem da oferta seletiva para a oferta democrática do ensino obrigatório, o qual, até 1967, correspondia aos quatro anos do curso primário e que dali em diante foi fixado nos oito anos do $1^{\circ}$ grau, implantado realmente em 1972. Tais dispositivos institucionais, entretanto, longe de conciliar crescimento quantitativo de atendimento e qualidade do ensino, provocaram o deslocamento do dualismo a que acima nos referimos: a massificação da oferta de ensino primário e secundário das redes estaduais e municipais determinou a volta dos filhos das famílias de classes médias para as escolas privadas. A fama da escola pública melhor foi substituída pelo critério mercantil: quanto mais alta a mensalidade, melhor a qualidade do ensino e, graças a ela, maiores as chances de os alunos conquistarem vagas nos cursos nobres da educação superior.

O quarto exemplo corresponde a um novo tempo do País, em que começa a diminuir a demanda de vagas na educação básica, em razão da redução drástica da natalidade - o que possibilitou criativos arranjos de equidade entre as ofertas dos entes federados e uma ousada expansão do ensino obrigatório, bem como das matrículas gratuitas na educação superior. Data de 1997 a implantação do Fundef e de 2007 a do Fundeb: fundos de manutenção e desenvolvimento do ensino fundamental e da educação básica, respectivamente. De 2009, o ensino obrigatório dos 4 aos 17 anos de idade.

O financiamento, teoricamente maior e mais equânime, possibilita a democratização da oferta, que ultrapassa a 50 milhões de matrículas nas três etapas da educação básica pública, e a valorização maior e mais universal dos educadores. O Fundef possibilitou ganhos expressivos nos salários do "magistério"; e o Fundeb, reforçado pela Lei do Piso Nacional do Magistério, de 2008, estende a valorização a todos os "profissionais da educação". Os ganhos mais espetaculares se registram na educação superior. De quatro milhões de matrículas em 2002 nos cursos de graduação, dos quais menos de um milhão gratuito, se evolui para oito milhões de estudantes, dos quais dois milhões em cursos públicos ou privados gratuitos e outros dois milhões em cursos com financiamento total ou parcial durante os estudos (FIES).

Essas conquistas se complementam por outras - das ditas "ações federais suplementares": na educação básica, programas de transporte de estudantes, de alimentação escolar, de material didático, de apoio à manutenção física das escolas e de formação de trabalhadores da educação - possibilitados por tributos complementares, chamados "contribuições sociais", entre as quais, a do "Salário Educação" e a da Contribuição para a Seguridade Social (Cofins) são as mais expressivas. Entretanto, esses mesmos avanços rumo à democratização e à qualidade estão eivados de contradições e limitações - que, na educação básica, focada pelo presente artigo, se expressam pelo modelo de financiamento, com duas políticas restritivas: uma que impede a real valorização dos 
profissionais da educação e outra que subordina estratégias de receita e investimento não à desejada qualidade da educação pública para todos, mas aos interesses dos capitalistas.

Essas contradições e limitações tecem os fios da história. Repitamos: de uma história onde comparecemos não como expectadores, nem somente como críticos, mas como sujeitos aptos a intervenções que aceleram seus rumos e transformam suas estruturas. Nas seções seguintes vamos abordar dois campos de conflitos complexos. O primeiro de pretensa unanimidade: a valorização dos educadores. $\mathrm{O}$ segundo da restrição de recursos financeiros, enfrentada pelo dispositivo do PNE que destina à educação recursos públicos equivalentes a 10\% do Produto Interno Bruto (PIB) - diante do que protestam ou tergiversam empresários e rentistas.

\section{Invertendo prioridades no pacto federativo}

Comecemos esta seção com dois informes e uma reflexão.

A primeira informação é que a ideia do piso nacional de salário dos professores nada tem de nova. Já constava da Lei Imperial de 1827, que "obrigava" as províncias a pagarem salários entre 200 e 500 mil réis anuais a mestres e mestras do ensino primário. E mais: já no século XX, quando a ministra da educação Esther de Figueiredo Ferraz tentou instituir um piso salarial para os professores de todo o Brasil (1982), com suplementação financeira federal para os da zona rural - que então constituíam cerca de 30\% do total de educadores.

A segunda informação, mais recente, é das manobras dos deputados do "centrão" durante a Constituinte de 1987/1988. Aprovada a Carreira Nacional do Magistério na Subcomissão de Educação, substituiu-se num primeiro momento a expressão por "piso salarial nacional" e no texto final se escreveu "piso salarial profissional do magistério" - dispositivo do art. 206 da Constituição Federal promulgada em 5 de outubro de 1988. Isso impediu que, na LDB de 1996, se regulamentasse o piso salarial profissional nacional, reivindicado desde 1985 pela atual Confederação Nacional dos Trabalhadores em Educação (CNTE) - então no valor de três salários mínimos por 20 horas semanais de trabalho. Mas em 2009, a Emenda Constitucional nº 59, fruto de mobilização da CNTE e de atuação de parlamentares progressistas, restabeleceu a unicidade ou nacionalidade do piso salarial profissional.

Nessas duas notícias se vê claramente as contradições dos discursos e das práticas, bem como dos comandos das autoridades financeiras e dos partidos hegemônicos na limitação dos gastos com salários dos professores da educação básica.

A reflexão que exponho a seguir é a contribuição mais radical deste texto para o debate da valorização dos educadores e da política de piso nacional numa República Federativa. Quais são os educadores da educação básica que seriam beneficiados 
pelo piso? Desde 1550, nas nossas escolas, temos três categorias de trabalhadores: os professores, os gestores e os funcionários, hoje conhecidos por "técnicos administrativos". Entretanto, quando se falava em valorização, só os docentes eram lembrados. Por várias razões, uma das quais era a da origem social dos não docentes - do estamento escravizado que só superou sua condição legal em 1888. De lá até hoje, o número desses servidores só fez aumentar, dada a variedade de funções sociais que se agregaram à tarefa que deu origem às escolas, à alfabetização e ao desenvolvimento do currículo de ensino. Não somente cresceu seu número, estimado hoje em dois milhões, igual ao dos professores, como aumentou sua escolaridade e consciência cidadã e sindical. Pergunta-se: o dispositivo do art. 206 da Constituição inclui os funcionários diplomados como técnicos em educação? Sem dúvida, pois o texto é claro: piso salarial nacional para os "profissionais da educação", não mais somente para o "magistério". A CNTE reivindica para eles o mesmo valor do piso do magistério, no caso dos formados em nível médio: $\mathrm{R}$ \$ 2.650,00 por 40 horas semanais. Consequência óbvia: mais verbas públicas para a educação básica pública.

Cabe agora voltar à crise salarial dos professores de um século atrás, que os levará à conquista efetiva do piso salarial 90 anos depois.

A grita dos professores contra seus baixos salários foi uma constante desde 1822. Mas as coisas se resolviam "naturalmente". Durante 100 anos permaneceu pequena a demanda por professores secundários, enquanto se feminizava o corpo docente nas escolas primárias rurais e urbanas. Além disso, importa lembrar que as professoras provinham de famílias de extratos médios. Não dependiam do salário para a sobrevivência. Da década de 1920 em diante, as coisas mudaram: explodiram as matrículas nas escolas primárias, multiplicaram-se as vagas de professoras primárias. As escolas normais começaram a receber moças de famílias proletárias que passaram a ocupar os empregos nos "grupos escolares" paulistas, mineiros, fluminenses e gaúchos - para citar os estados mais urbanizados. Nas escolas rurais, arranjos conservadores prolongaram a vigência dos baixos salários: as professoras eram na maioria filhas de fazendeiros ou comerciantes, a que se juntavam docentes "leigas", sem formação de magistério normal, que se contentavam com um pequeno salário que complementava outras fontes de sobrevivência.

Nas grandes e médias cidades, um expediente criativo dos gestores paulistas veio para solucionar o problema mais agudo da falta de salas de aula e de professoras: a duplicação de turnos para os alunos e de jornadas ou cargos para os mestres. Exemplificando. Uma professora trabalhava de seis a sete horas diárias, das $8 \mathrm{~h}$ às $16 \mathrm{~h}$ horas, com intervalo para almoço, em uma turma de 30 alunos, fazendo jus a um salário. Premido pela demanda, o governo de São Paulo convidou essa professora a reger uma turma de 30 alunos no turno matutino, das 7 h às 11h, e outra no turno vespertino, das $13 \mathrm{~h}$ às 17h. Não houve acréscimo de despesas de capital (prédio e equipamentos) e a duplicação de salários favorecia "providencialmente" as novas professoras das classes 
populares. Mais contentes ainda ficaram as que continuaram a ganhar o mesmo salário com metade de horas trabalhadas. Afastava-se, assim, o receio de os mestres se sindicalizarem, como aconteceu com os das escolas privadas, e de contestarem a situação com greves que pipocavam nas outras categorias de trabalhadores. Os professores das escolas secundárias públicas ganhavam bons salários e, à medida que elas começaram a se multiplicar, o sistema taylorista do currículo, com pagamento por horas/aula, permitiu que aumentassem seus salários, acumulando trabalho em outras escolas públicas ou privadas; ou, melhor ainda, em cursos superiores que proliferaram de 1930 em diante. Assim, até os meados do século XX, o "mais trabalho", em limites toleráveis, propiciou a todos, inclusive ao Estado que financiava a educação, a solução pacífica do conflito, embora com crescente prejuízo dos estudantes, como poderemos aprofundar na última seção deste artigo, ao refletirmos sobre a qualidade da aprendizagem sob más condições de trabalho dos educadores.

Como se originou a ideia do piso salarial nacional, originalmente pensado para os docentes?

Nos países unitários, sem a existência de entes federados autônomos, as carreiras e salários dos servidores públicos são únicas, em razão da própria organização política do Estado. Um professor no Uruguai ou na França tem o mesmo regime de trabalho e a mesma remuneração: em Montevideo ou Rivera, em Paris ou Avignon. Numa República Federativa como a do Brasil, principalmente quando os entes são autônomos, carreiras e salários diferentes se multiplicam nos 26 estados e 5.570 municípios. Nem mesmo o valor do salário mínimo foi respeitado, durante muitos anos. Mais complicado ainda: embora os percentuais de impostos tenham um mínimo igual (25\%), as receitas e as demandas de matrículas, que regulam as despesas por aluno e os valores dos salários, podem ser muito díspares entre si. O exemplo do rico município de Paulínia/SP, recordista de ICMS per capita no Brasil, remetia a condições de Primeiro Mundo. Em outro extremo, municípios de economia primária tradicional exibiam disponibilidades de recursos per capita até 30 vezes menores. Daí a necessidade de outro mecanismo de unificação, em nome da equidade.

O piso salarial já tinha sido aventado por cientistas da educação, como Anísio Teixeira e Lourenço Filho, entre 1934 e 1950. Mas a diferenciação dos valores de arrecadação de impostos, tornada ainda mais complexa com a criação das transferências constitucionais a partir de 1946 (Fundo de Participação dos Estados e dos Municípios no âmbito da União e Fundo de Distribuição do ICM no interior de cada estado) inibiu a ideia de um Fundo Educacional Único e mais ainda de um piso salarial profissional - este último também inviabilizado pela preponderância dos "leigos" na maioria dos municípios menores. Em 1962, Anísio foi encarregado de elaborar um PNE, exigido pela LDB de 1961 - Lei nำ 4.024. Nele incluiu fundos equalizadores para o ensino primário, secundário e superior, com preponderância de verbas federais, sem a ousadia de fazer 
circular entre os entes federados os frutos de suas respectivas arrecadações de impostos. Entretanto, o PNE de Anísio, mesmo que tímido, foi abortado pelo Golpe Militar de 1964, que enquadrou a educação na subserviência dos projetos de desenvolvimento da agricultura e da indústria.

A década de 1960 viu nascer a Confederação de Professores do Brasil (CPB), num tempo de intensa efervescência política e de mobilizações trabalhistas. Os professores ou já se tinham organizado em associações estaduais ou passaram a fazê-lo. Daí para as greves foi um pulo rápido, mesmo na vigência do regime de exceção instaurado em 1964. A ideia do piso não tinha condições de vicejar, ainda mais que o mecanismo da dupla jornada proliferou e se multiplicaram as oportunidades de ascensão interna em carreiras estaduais de ensino de $1^{\underline{o}}$ e $2^{\underline{o}}$ graus, e de transmigração para novos postos de trabalho em milhares de vagas das faculdades públicas e privadas criadas de $1970 \mathrm{em}$ diante. Em novo front de mobilização, as associações pressionaram o governo federal a criar a "aposentadoria especial" dos professores, com menos cinco anos de serviço que os outros trabalhadores, e os governos estaduais e municipais a instituírem gratificações nos seus planos de carreira, de todos os tipos: trabalho em locais de difícil acesso, em classes de deficientes, em turmas de alfabetização, em funções de coordenação e gestão, e até mesmo o "adicional de pó de giz", que se aplicava aos que não se enquadravam nas situações anteriores.

Talvez a variável mais significativa que freou a reivindicação do piso foi os ganhos com progressão vertical nas carreiras, tornadas obrigatórias com a Lei n⿳0 5.692, de 11 de agosto de 1971, que instituiu a Reforma de Ensino do $1^{\circ}$ e $2^{\circ}$ Graus. Aproveitando da fragmentação do processo formativo, inúmeras carreiras estaduais e de municípios maiores instituíram progressões "verticais", do vencimento básico correspondente ao diploma de magistério de $2^{\underline{o}}$ grau, até títulos de pós-graduação que, somadas a progressões "horizontais" por tempo de serviço e outros critérios, resultavam em salários-teto até 500\% maiores! Essas diferenças eram "palatáveis" aos governos que as concediam em razão de somente uma minoria possuir os títulos maiores e maior tempo de serviço. Mas os "crescimentos vegetativos" das folhas de pagamento, principalmente das redes estaduais, impulsionaram dois movimentos: o de municipalização da educação infantil e do ensino fundamental estaduais e o de arrocho do valor do vencimento-base, mesmo corroído pela inflação. Nesse cenário, implantar piso nacional, como instrumento de valorização dos educadores, era suicídio para os gestores e ameaça à necessidade premente de expansão das matrículas.

As associações e a CPB, em seus congressos, durante a Ditadura Militar, usavam a diferenciação de tabelas salariais entre estados mais ricos e mais pobres para animar a categoria a reivindicar maiores remunerações e "penduricalhos", mas não se atreviam a colocar em seu plano de lutas o piso salarial nacional unificado. 
O primeiro congresso da CPB que aprovou a reivindicação do piso nacional - três salários mínimos para os professores com nível médio em regime de 20 horas semanais - foi o de Fortaleza, em 1985, sob a presidência do prof. Hermes Zanetti, que tinha o mesmo cargo no CPERS, uma das mais ativas associações de professores do país. A resposta do poder veio a galope: a Constituição de 1988 proibiu que houvesse qualquer vinculação institucional, inclusive de remunerações de servidores públicos, com o valor do salário mínimo, e retirou o caráter nacional do piso profissional do magistério, que a CPB tinha alcançado na Constituinte, com o deputado Zanetti na presidência da Subcomissão de Educação e João Calmon como seu relator.

O mais duro golpe contra o piso, entretanto, ocorreu anos depois, em 1996, quando o acúmulo das mobilizações sindicais dos trabalhadores da educação havia chegado ao auge e se ultimava a aprovação da LDB e do esquema de "valorização do magistério", viabilizados pela maioria política conquistada pelo governo de Fernando H. Cardoso.

Dediquemos um parágrafo para o Acordo Nacional (1994) e outro para a Emenda Constitucional no 14 .

Depois da unificação sindical dos educadores das redes públicas em congresso da Confederação dos Professores do Brasil em Aracaju, em 1990, que deu origem à CNTE, deu-se uma escalada sem precedentes na filiação de professores, especialistas e funcionários aos sindicatos no Distrito Federal e em todos os estados, o que alimentou mobilizações e greves cada vez mais apoiadas pela população. A reivindicação pelo piso nacional, que ficara a meio caminho no texto da Constituição de 1988, alimentava os debates não somente nos congressos anuais da CNTE, como também na academia e nas mobilizações cada vez mais frequentes, em protesto à falta de política de valorização do Governo Federal nos três anos de Collor. Na gestão de Itamar Franco, o ministro da Educação, Murílio Hingel, abriu espaço para participação social na construção do Plano Decenal de Educação. Nessa discussão, ficou claríssimo que a qualidade da educação básica pública dependia essencialmente da valorização salarial do magistério e esta última só viria com uma política e com recursos federais. $\mathrm{O}$ argumento visível a todos era a diferença entre salários de professores e desempenho dos estudantes nas escolas federais e nas então chamadas "subnacionais" (estaduais e municipais). Daí para um Acordo Nacional para implantação do piso nacional de R $\$ 300,00$ para o professor com normal médio por 40 horas semanais, foi somente uma questão de discussão e forte articulação entre MEC, Consed, Undime e CNTE: no dia 19 de outubro de 1994, o Presidente Itamar assinou o termo do Acordo para vigência a partir de janeiro de 1995, comprometendo $9 \%$ da receita dos impostos federais para sua viabilização - metade dos 18\% destinados à MDE pelo art. 60 do Ato das Disposições Constitucionais Transitórias (ADCT). Tudo combinado?

Na realidade, faltava o principal ator que tomaria posse em $1^{\circ}$ de janeiro de 1995 como presidente, FHC. Seu ministro da Educação, Paulo Renato Sousa, economista e 
ex-secretário da maior rede estadual de educação básica da América Latina, então com cinco milhões de estudantes e mais de 300 mil servidores da educação, tinha outra ideia para valorizar a educação. Admitia, sim, uma leve complementação do MEC para pagamento de salários de educadores estaduais e municipais, mas nada de soluções "sistêmicas": o foco seria somente o ensino fundamental obrigatório de oito anos; e, para conseguir elevar os salários, um arranjo simples, já estudado por seus auxiliares Barjas Negri e Eunice Durham, que misturava 15\% das receitas estaduais e municipais de MDE (60\% do total dos $25 \%$ vinculados constitucionalmente pelo art. 212) no âmbito de cada estado e os redistribuía pelas respectivas redes de acordo com o número de matrículas de cada uma. Não precisaria haver um piso nacional, porque eram instituídos fundos estaduais amarrados por normas nacionais. Em cada estado se construiria uma "remuneração média potencial”, com valor mínimo garantido pela União. Era o Fundef. E os funcionários da educação, para os quais a CNTE também reivindicava o piso? Nos corredores do MEC e nas reuniões do Conselho Nacional de Educação, se comentava: “Piso nacional para todos os trabalhadores da educação, isso é coisa do PT, deixa para quando o Lula ganhar a eleição... E os professores do ensino médio e da educação infantil, que ficaram fora do Fundef, não serão 'valorizados' "? O PSDB, hegemônico e respaldado pelo PFL, respondia: "sobram $40 \%$ dos impostos vinculados e ainda mais a receita do IPTU, ISS e ITBI municipais, que não entram na cesta do Fundef".

Em 1998, depois de muitos arranjos e negociações (inclusive a de destinar 60\%, no mínimo, das receitas dos fundos para o pagamento dos professores em exercício em cada rede pública de ensino fundamental), o Fundef foi plenamente implantado. Nove estados - o Pará e oito do Nordeste - foram aquinhoados com complementação da União, que possibilitou ganhos reais significativos para os professores onde os salários eram miseráveis, abaixo do salário mínimo nacional. Talvez essa fosse uma das razões pelas quais FHC se reelegeu em outubro, não tanto com os votos dos professores, mas com a influência dos prefeitos beneficiados. Em 1997, já na vigência da Emenda Constitucional no 14, que, entre outras mudanças, criou o Fundef pela nova redação do art. 60 do ADCT, somente o Pará se beneficiou, e muito, com o Fundef: ao final do ano publiquei um estudo de suas consequências na capital, Belém, em Bragança e em Bonito. O título é sintomático: O Fundef e seus Pecados Capitais.

Em 1999, deputados do PT protocolaram a Proposta de Emenda à Constituição n⿳o 103, sugerindo a implantação do Fundeb, estendendo a política de fundos a toda a educação básica e a valorização dos profissionais da educação, que incluiria os funcionários profissionalizados e o mecanismo do piso salarial nacional. Nem Comissão foi instaurada para sua tramitação, enquanto a aliança PSDB-PFL governava o Brasil e a direita neoliberal era hegemônica no Congresso Nacional. Entretanto, nas ruas, foi se acumulando uma tendência de mudança, de políticas alternativas às ideias neoliberais adotadas nos oito anos de FHC. Em 2002, em ampla coligação, Lula foi eleito presidente. O MEC, em 
três anos, passou por três titulares: Cristovam Buarque, Tarso Genro e Fernando Haddad. Em 2005, o presidente encaminhou ao Congresso a PEC que criava o Fundeb. Era outra a correlação de forças partidárias. Num primeiro momento, não se incluía o mecanismo do piso salarial no texto do art. 60 do ADCT emendado. Mas, como indica Juçara Vieira em sua tese de doutorado, não havia como "não tomar partido" na questão do piso. Em 1996, o PSDB o vetou. Agora, o PT o adotou e falta ainda um estudo mais aprofundado ou um tempo de contradições para explicar sua aprovação por unanimidade partidária.

\section{Partindo de direitos e capacidades, não de privilégios e limitações}

Esperamos que, pelas reflexões de caráter conceitual e histórico da seção anterior, tenhamos lançado as bases para concluir que:

a. Numa educação escolar democrática não se pode priorizar um nível ou uma etapa em detrimento de outro (a).

b. Num processo democrático de valorização de educadores, não se pode priorizar profissionais do magistério às custas da exploração das outras categorias, que aqui reunimos sob o nome de "funcionários da educação".

c. Num processo de financiamento de educação, principalmente quando se pensa na sua relação com a qualidade da educação pública socialmente referenciada, não cabe alargar as desigualdades entre custos por aluno de um nível ou etapa em relação a outro.

d. Numa República Federativa, com autonomia dos entes em fixar orçamentos de receitas e despesas, se é impossível fechar questão sobre carreiras unificadas dos servidores da União, dos estados e dos municípios, é fundamental possuir leis e normas que minimizem as desigualdades salariais - o que justifica a criação de fundos articulados e de mecanismos de garantia da equidade nas remunerações, como a do piso salarial nacional.

Para dar prosseguimento e unidade aos argumentos, concluímos nesta seção a descrição dos fundos, pela criação e implementação do Fundeb, e a reflexão sobre o CAQ, no prolongamento do piso salarial.

À emergência da PEC nº 103, em 1999, o Governo FHC deu uma resposta rápida. O Fundef resolvia em grande parte as questões mais urgentes de financiamento do ensino fundamental. Mas, desde 1998, ele havia criado um "reboliço geral": a disputa por matrículas, que passaram a ser o mecanismo de atração dos recursos de cada fundo estadual e, mais ainda, das possíveis verbas de complementação federal. Nesse ajuste de contas e de encargos, as finanças estaduais foram, em geral, drenadas para os cofres dos municípios, onde era maior o número de matrículas e menor a receita de ICMS e FPM/FPE. Assim nasceu o Fundebinho, socorro voluntário do MEC para financiar o ensino médio dos estados que provavam insuficiência de seus recursos para a MDE. Ajuda emergencial já havia ocorrido no Rio de Janeiro, onde metade do ICMS estadual 
em 1988 passava automaticamente para as redes municipais, com mais matrículas. Mais do que "pecados", o Fundef tinha limitações práticas insuperáveis, por seu caráter focal que desconsiderava as desigualdades de arrecadação e de distribuição de matrículas em cada estado. Foi Lula ganhar em 2002 e se começou a construir o Fundeb, dentro do governo e do movimento sindical, mesmo porque o Fundef tinha esgotado suas virtudes e a União se limitava a complementações residuais, para três estados: Pará, Bahia e Maranhão. Diga-se de passagem, com suspeitas de que por lá se inflava o número de matrículas com alunos fantasmas ou "transferidos" da Educação de Jovens e Adultos (EJA) para as turmas regulares diurnas.

O Fundeb foi fruto de uma PEC de iniciativa do Lula em 2005. Pontos positivos: a abrangência passava do ensino fundamental "regular" para todas as etapas e modalidades da educação básica (com exceção dos cursos estritamente profissionais); a cesta de impostos do fundo se ampliava para o ITR e o ITCD (imposto estadual sobre heranças); a complementação da União se fixava em "no mínimo" 10\% da receita total do fundo (depois de três anos de gradualidade a partir de 2007 com R 2 bilhões); e as matrículas passaram a ter valores mais próximos dos custos reais, incluindo diferenças entre tempo parcial e tempo integral, da creche ao ensino médio. O que aqui mais nos interessa: para a valorização, não mais do magistério, mas dos profissionais da educação, do constructo do "salário médio potencial", passou-se ao piso salarial nacional. Mas, atenção! Dos "profissionais do magistério", não dos profissionais da educação.

Estas e outras questões agitaram entidades e parlamentares em memoráveis sessões na tramitação da PEC, que se transformou na Emenda nº 53, de 2006, da Lei nํㅜ 11.494, de 2007, que regularizou o novo fundo e da Lei do Piso, de nº 11.768, de 2008. Hoje, em 2016, podemos celebrar os avanços inegáveis, como a inclusão das creches públicas, a destinação de até $15 \%$ da receita do fundo para a EJA e a democratização dos conselhos estaduais e municipais de controle, mas temos que ressaltar seus custos: inclusão das creches e pré-escolas comunitárias gratuitas, a derrota da proposta da CNTE de destinação de $80 \%$ da receita do fundo para pagamento dos profissionais da educação e, principalmente, a manutenção de um critério de fixação de valor mínimo por aluno pela União sem a prevalência do CAQ, conceito nascido na CNTE na década de 1990 e que se difundiu em razão de esforços da Campanha Nacional pelos Direitos à Educação.

É sobre o CAQ que dedicaremos as próximas páginas deste artigo: só a implantação dele como critério de financiamento e de distribuição de recursos garantirá a verdadeira qualidade da educação pública no Brasil, até hoje dependente das "limitações do Tesouro Nacional".

Para fundamentar a compreensão orgânica e operacional do CAQ, comecemos por algumas definições.

Capacidade contributiva - na Constituição Imperial, publicada em 25 de março de 1824, escreveram-se estes dois incisos no art. 159: “XV - Ninguém será isento de 
contribuir para as despesas do Estado em proporção de seus haveres. [...] XXXII - A instrução primária é gratuita a todos os cidadãos."

Assim, fica claro: para fazer face às despesas do Estado, que, no âmbito da educação evoluíram da "instrução primária" para todos os níveis (art. 205 da atual CF), as pessoas físicas e jurídicas são obrigadas a contribuir com o pagamento de tributos, proporcionais às suas posses (impostos patrimoniais), às suas rendas e salários (IR) e ao volume de seu consumo de bens e serviços (ICMS, IPI, ITBI e ISS). É óbvio que a expansão dos investimentos e gastos do Estado deve ser feita com ampliação da receita dos tributos, arrecadados proporcionalmente à capacidade contributiva dos cidadãos e empresas. Não é isso que ocorre: em relação a suas posses, rendas e salários, os pobres pagam muito mais tributos do que os ricos. Por isso, a reivindicação histórica da CNTE de uma Reforma Tributária, que passa por redução de impostos sobre consumo e elevação das alíquotas do Imposto sobre a Renda e/ou a implantação do Imposto sobre Grandes Fortunas (IGF), já constante da atual Constituição.

Capacidade de arrecadação - os tributos se classificam em impostos, taxas e contribuições sociais. No caso do financiamento da educação, a legislação prevê receitas de impostos federais, estaduais e municipais para a MDE (no mínimo 18\% da União e 25\% dos estados, municípios e Distrito Federal); de contribuições sociais (100\% do Salário Educação) e percentuais voluntários de outras contribuições (por exemplo, da Cofins) derivam as despesas da União com o Programa Nacional de Alimentação Escolar; e de taxas, desde que não firam o princípio da gratuidade do ensino em estabelecimentos públicos (art. 208 da CF) - taxas de vestibulares e concursos, por exemplo. Assim, cabe à União, ao Distrito Federal, aos 26 estados e 5.570 municípios arrecadar os tributos para a educação. Desde o "subsídio literário" das Aulas Régias, regulamentado em 1772, há uma visível subarrecadação dos tributos que se destinam orçamentariamente à educação, em todas as esferas administrativas. Um exemplo patético atual é a receita de Imposto Territorial Rural que foi de cerca de R\$1 bilhão em 2015 e corresponde a 600 milhões de hectares tributáveis: ou seja, menos de $\mathrm{R} \$ 2,00$ por hectare/ano. No financiamento, o grande avanço se deu a partir de 1934, quando se criou a vinculação obrigatória de percentuais de impostos federais, estaduais e municipais à MDE até se chegar, em 1988, aos mínimos acima registrados. Registre-se que na Ditadura Vargas e na Militar o percentual da União foi temporariamente abolido pelas Emendas Constitucionais de 1937 e de 1967. Atente-se, portanto, que há uma relação direta entre democracia e vinculação de impostos à MDE.

Direito à educação escolar - também é óbvio que a expansão de gastos e investimentos em educação se relaciona à ampliação dos direitos aos cidadãos: para se prover ensino obrigatório gratuito de quatro anos, que vigorou de 1824 até 1967, requereu-se muito menos recursos financeiros do que atualmente, quando a gratuidade é garantida pelo ensino obrigatório de 4 a 17 anos, além do opcional nas creches (0 a 3), na EJA e 
nas universidades públicas. Ora, quanto maiores forem os direitos à educação escolar, maior deve ser a arrecadação de tributos e o percentual do PIB aplicado à educação.

Na prática, estamos longe de resolver essa equação: além de a arrecadação ser insuficiente, os beneficiários das verbas da educação, especialmente nas universidades federais, são os integrantes das famílias de melhor condição financeira. Daí a importância da política de equidade da Lei de Cotas para ingresso na graduação e pós-graduação. E da oferta urgente de cursos de EJA na modalidade profissional: basta lembrar que são mais de 70 milhões os jovens, adultos e idosos sem a educação básica concluída. Assim, atingir os 10\% do PIB em educação a curto prazo é urgência constitucional para pagarmos uma imensa dívida histórica com os menos instruídos dos brasileiros. Isso supõe luta sem trégua à imunidade, sonegação e isenções fiscais. Imunidade no caso da não cobrança do ICMS dos produtos exportados (art. 155 da CF); sonegação em especial do IR e outros tributos onde se difundiu essa cultura anticívica; e isenções, que podem ser por renúncia legal com o argumento de incentivos a empresários ou por subarrecadação, que ocorre com o ITR, IPI, IR, IPTU, ITCD e ITBI - estas últimas de responsabilidade dos próprios governos, muitas vezes como atitudes clientelistas que configuram comércio de votos.

Qualidade do investimento - tem-se argumentado muito atualmente que as receitas de tributos para a educação são suficientes e que os problemas são de má gestão ou mesmo de corrupção no uso das verbas públicas. Não se pode "tapar o sol com a peneira" quando escutamos na mídia casos de desvios de verbas da merenda e até do Fundeb, destinado na maior parte (ou na totalidade, em muitos municípios) ao pagamento de trabalhadores da educação básica. Mas, além de se afirmar que os recursos financeiros são insuficientes quantitativa e qualitativamente para efetivar os direitos de mais de 100 milhões de brasileiros à educação básica, há que se fazer uma distinção conceitual na questão das despesas. Primeiro, refutar a tese difundida por muitos de que quaisquer gastos em educação são investimentos. Não é verdade: além dos desvios de finalidade, que desobedecem, por exemplo, ao disposto nos arts. 70 e 71 da LDB que definem o que se pode considerar ou não como MDE, temos que ter presente que "investimento" tem a ver essencialmente com despesas que assegurem o alcance do objetivo, ou seja, que se fazem em vista de um bem futuro inscrito como finalidade legal da educação ou dos projetos político-pedagógicos das escolas. Damos dois exemplos de gastos que não são investimentos e poderiam até ser considerados desperdícios ou mesmo crimes: primeiro os $\mathrm{R} \$ 3$ bilhões anuais que estados e municípios usam para pagamento de professores de inglês durante quatro anos do ensino fundamental e três do médio, que resultam em quase nenhuma aprendizagem dos estudantes (o que, por sua vez, alimenta a indústria dos cursos de idioma, que faturam mais de R $\$ 7$ bilhões anuais); segundo, os gastos com concursos públicos para professores alfabetizadores e muito mais com os pagamentos dos aprovados (por não se sabe quantos anos...) que não 
tiveram suas competências devidamente apuradas nas provas de ingresso nas respectivas carreiras. Aqui vale duas reflexões: é plausível admitir a um concurso para anos iniciais do ensino fundamental alguém com o "título" de pedagogia, que nunca alfabetizou uma criança ou adulto e não cumpriu em seu curso as 300 horas obrigatórias de prática de ensino? A quem interessou a privatização da formação das professoras em nível superior que antes era feita nos cursos normais, na maioria das redes estaduais e até municipais? Raciocinando agora em sentido inverso: todos os recursos despendidos na formação pública de qualidade dos professores (que se dá inicialmente nos cursos normais) e dos funcionários da educação (nos institutos federais de Educação, Ciência e Tecnologia e em escolas de ensino médio estaduais) - estes sim são investimentos no futuro da qualidade de todas as etapas da educação básica.

Custo-aluno-qualidade (CAQ) - definição legal da LDB, art. 3ํ, IX: a qualidade é a soma de insumos que concorrem com a aprendizagem dos estudantes. Prédios bem construídos em espaços amplos e ecologicamente ocupados, salas arejadas e com temperatura adequada, biblioteca e videotecas articuladas com os currículos, alimentação saudável, jornada de pelo menos sete horas, turmas com número de estudantes pedagogicamente coerentes com o processo de ensino-aprendizagem, conteúdos curriculares compatíveis com a cultura dos estudantes e objetivos dos cursos e, principalmente, profissionais da educação (gestores, professores e funcionários) bem formados e bem pagos.

Ora, esses insumos se traduzem em custos para quem "mantém" a escola. Aqui é útil continuar a reflexão comparando custos, presentes na educação pública e na privada, com preços, que funcionam somente nas escolas particulares, sob forma de "mensalidades" ou "anuidades". Na escola privada, de certa forma, os custos dos insumos podem aumentar com total elasticidade: os preços das mensalidades não têm limites, a não ser os do mercado, que refletem o poder de compra das famílias e o valor que setores delas dão ao produto "educação". Já nas escolas públicas os recursos do Estado são orçamentariamente finitos e disputados por várias políticas públicas. Daí a importância da capacidade de arrecadação e da vinculação dos impostos à MDE, como garantia de orçamentos mínimos para a educação e de "valores-mínimos-por-aluno". Daí ainda a opção fundamental de uma sociedade democrática em combinar a universalização do atendimento educacional a todos os que a ele têm direito numa média de "gasto-por-aluno" que leve ao aprendizado e à sua qualidade.

Pode-se perfeitamente analisar a evolução das matrículas combinada com a evolução do "gasto-real-por-aluno" e do salário médio dos professores e dos funcionários. Na perspectiva de uma educação pública de qualidade, o CAQ é o elemento de tensão entre a demanda de direitos por educação escolar, a capacidade de poupança pública e investimento das receitas em educação pública e as opções políticas que levam a maior ou menor qualidade, reflexo da correlação de forças numa sociedade de classes que se acostumou a ter o duplo privilégio de pagar menos tributos (atente-se à redução das 
alíquotas de IR de 45\% na Ditadura Militar para 25\% na CF de 1988) e a gozar da universidade estadual e federal gratuita onde os custos-reais-por-aluno costumam ser de cinco a dez vezes maiores que na educação básica pública.

O que aconteceu na LDB, no Fundef e no Fundeb em relação ao CAQ?

Na LDB, o art. 75 previa uma distribuição de recursos entre as três esferas segundo uma suposta "capacidade de atendimento" de cada rede estadual ou municipal: que deveria ser a divisão entre os recursos arrecadados de impostos vinculados à MDE por um valor-mínimo-qualidade, que nunca chegou a existir. Por quê? Em 1997, 12 dias depois da sanção da Lei no 9.394 (LDB, de 20 de dezembro de 1996), o Governo FHC lançou o "experimento" do Fundef do Pará, arbitrando um suposto valor-mínimo-nacional-anual de $\mathrm{R} \$ 300,00$ que definiu a complementação federal para aquele único estado (coincidentemente do PSDB). Estes $\mathrm{R} \$ 300,00$ por aluno não representavam um valor de soma de insumos que garantissem qualidade (MONLEVADE, 1997), muito menos refletiam uma comparação honesta com a média das anuidades de mercado praticadas nas escolas privadas naquele ano (estimadas em $\mathrm{R} \$ 600,00$ ), mas tão somente uma decisão política do ministro Malan, da Fazenda, que pudesse resultar numa complementação pífia para os nove estados que a receberiam em 1998, ano da reeleição de FHC como presidente do Brasil, que ocorreu com vitória em especial nesses estados beneficiados. Já a tramitação do Fundeb teve o bombardeio da CNTE e da Campanha pelos Direitos à Educação que encamparam o conceito de CAQ (mitigado pelo de Custo-Aluno-Qualidade-Inicial - CAQI) e provocaram um significativo avanço da complementação da União para os fundos estaduais, gradativamente crescente até "no mínimo" $10 \%$ da receita total do Fundeb.

Registrem-se três problemas enfrentados de 2010 para cá: primeiro, a rigidez das autoridades financeiras do PT no Ministério da Fazenda em considerar o mínimo de 10\% como máximo, obedecendo ainda ao critério de liberação no ano fiscal de somente $85 \%$ da dotação anual; segundo, de 2014 para cá, a diminuição, em valores reais, da receita total do Fundeb, como consequência da contração econômica e decréscimo geral de arrecadação de impostos (com exceção do IPVA e ITCD); terceiro, a consequência trágica, apontada por poucos, mas sentida por muitos, tem sido que o valor mínimo anual por aluno (versão tímida atual do CAQ) e o valor do piso salarial profissional nacional para os profissionais do magistério só têm tido aumento porque as matrículas nas escolas públicas têm diminuído.

Não compete a este texto investigar as causas dessa "deflação de matrículas", embora três fenômenos sejam óbvios e devam ser registrados: a diminuição do número de nascimentos (de 4 milhões no início do Fundef para 2,8 milhões em 2015), a procura maior pelas escolas privadas (no caso da educação superior acelerada por programas federais como o Prouni e FIES) e a "inação" de estados e municípios na oferta de vagas na EJA, onde, mesmo com uma demanda potencial de 70 milhões de jovens, adultos 
e idosos, as matrículas públicas desabaram de cinco para dois milhões nos últimos 15 anos, em dados aproximados.

Pergunta-se: o que se faria com um eventual aumento geral de matrículas nas redes públicas, que timidamente ocorreu em 2015 nas creches e cursos profissionais médios integrados? Sem uma retomada no crescimento da arrecadação, que de certa forma independe da volta do crescimento do PIB, o valor mínimo do Fundeb e o do piso salarial profissional nacional pelas regras legais diminuiriam! Com o quadro atual de inflação, a consequência imediata seria a desvalorização salarial, a menos que...

\section{Conclusões nem tanto conclusivas}

Estamos às vésperas de um momento crucial na política brasileira e na política de financiamento. De um lado, ou ocorre o impedimento definitivo da presidenta Dilma ou ela dificilmente terá aprovados no Congresso seus projetos até o fim do segundo mandato, com quase dois terços de parlamentares na oposição. De outro lado, a CNTE pressiona o governo para cumprir o art. 206 da Constituição, que prevê o piso salarial nacional para todos os profissionais da educação, que no anteprojeto da CNTE é de R 2.650,00 por 40 horas semanais de quem tem formação técnico-pedagógica em nível médio. Esse valor corresponde aproximadamente ao que prevê o CAQI - um custo-aluno-qualidade não ideal, mas inicial, em vista de aproximação gradativa de investimento no insumo - salário que possibilitasse a dedicação de todos os professores e funcionários técnicos a uma única jornada de 40 horas semanais. Para isso, são imprescindíveis mudanças na Constituição, para assegurar 90\% dos recursos do Fundeb para os profissionais da educação e isentar esses pagamentos do cômputo dos mínimos de gastos com pessoal previstos na Lei de Responsabilidade Fiscal.

O Brasil nasceu dividido, desde 22 de abril de 1500. Trezentos e mais anos de colonização e de escravidão deram origem a dois campos distintos: os que têm bens de produção e os que vendem sua força de trabalho. Mais recentemente, também os que têm bons salários (digamos, bem acima da média de R 3 mil líquidos) estão num campo e os que ganham até três salários mínimos estão em outro campo. Entre os funcionários públicos, existe quase a mesma divisão, com a diferença de que as progressões de carreira dão esperança aos de baixo para passar para o grupo dos de cima. Qual é a reação do capitalismo? Terceirização de funcionários, processo já avançado, dos corredores do MEC até as escolas municipais; e transformação das escolas públicas em organizações sociais, com terceirização também dos professores, como ocorre "tranquilamente" nos 100 centros de educação infantil inaugurados pelo PT e PSB no Distrito Federal, em 2014 e 2015, respectivamente. Enquanto isso, na educação superior, tem-se a conquista inédita de dois milhões de alunos de universidades públicas e institutos federais 
gratuitos, mais dois milhões de estudantes com bolsas integrais do Prouni e FIES nas instituições privadas.

Como se vê, o princípio da universalização do acesso evolui rapidamente no sentido vertical, com a população conquistando mais e mais títulos de graduação e pós-graduação. De outro, o acesso à cultura de massas pelas populações adultas e pobres se resume aos programas de TV, mais de entretenimento do que de aprendizagem crítica. Em todos os níveis, etapas e modalidades de ensino, a qualidade do desempenho dos estudantes, medida pelos critérios tradicionais (travestidos de pseudocientificidade), estaciona ou diminui, inclusive nos cursos superiores. A falta geral de criatividade tecnológica, escancarada pela falta de marcas brasileiras de automóveis, eletrônicos e eletrodomésticos, denuncia a fragilidade de nossas instituições de pesquisa, inclusive das universidades públicas, onde os salários dos professores no topo da tabela são os maiores da América Latina. Ou seja, em que apartheid nos meteram: nas universidades e institutos federais nem se fala em "piso salarial", tido como "coisa de pobre", estratégia de sindicalistas de porão. No Governo Sarney, a Andes conseguiu a isonomia dos salários dos docentes pelas remunerações mais altas em cada classe...

Esta é a educação e o Brasil que a CNTE tenta transformar. Conseguirá? As lutas e o tempo responderão. A implantação de um CAQI médio na educação básica no valor de R\$ 5 mil, para financiar 100 milhões de matrículas, metade das quais em tempo integral, custar-nos-ia hoje, no mínimo R $\$ 500$ bilhões, cerca de 8,5\% do PIB, a que se devem somar no mínimo 2,5\% do PIB para a educação superior e profissional pública. Conseguiremos uma receita de R $\$ 660$ bilhões para se chegar aos 11\% do PIB? Impossível não é, principalmente porque nas 100 milhões de matrículas se incluem 40 milhões de EJA, sabidamente um número de esforço passageiro. Mas as forças privatizantes, que prevalecem no cenário da crise, certamente se insurgirão contra qualquer aumento expressivo de carga tributária. Mas temos que insistir: a função do CAQ é deslocar a política para o rumo certo: não partir de privilégios, limitações e divisões, mas de direitos, capacidades e qualidades. Somos 200 milhões que vivem uma dura realidade, temperada por esperança. Outros cinco milhões se esbaldam e defendem seus privilégios. OCAQ é um divisor de propostas de educação pública, entre a esperança de emancipação e qualidade no futuro e a teimosia do Brasil dividido do passado, eleito pesadelo do presente.

Recebido em dezembro de 2015 e aprovado em fevereiro de 2016 


\section{Referências}

BRASIL. Constituição (1824). Constituição Política do Império do Brazil. Rio de Janeiro: Alvarás e Cartas Imperiaes, 1824. Disponível em:

<http://www.planalto.gov.br/ccivil_03/constituicao/constituicao24.htm>. Acesso em: 12 maio 2016.

. Lei de 15 de outubro de 1827. Manda crear escolas de primeiras letras em todas as cidades, vilas e lugares populosos do Império. CLBR, Rio de Janeiro, 1827. Disponível em: <http://www.planalto. gov.br/ccivil_03/leis/LIM/LIM-15-10-1827.htm>. Acesso em: 5 maio 2016.

Constituição (1934). Constituição da República dos Estados Unidos do Brasil. Rio de Janeiro: Assembleia Nacional Constituinte, 1934. Disponível em: <http://www.planalto.gov.br/ccivil_03/ constituicao/constituicao24.htm>. Acesso em: 12 maio 2016.

Lei n⿳ำ 4.024, de 20 de dezembro de 1961. Fixa as Diretrizes e Bases da Educação Nacional. Diário Oficial da União, Brasília, DF, 27 dez. 1961. Disponível em: <http://www.planalto.gov.br/ ccivil_03/Leis/L4024.htm>. Acesso em: 15 nov. 2010.

Lei n⿳0 5.692, de 11 de agosto de 1971. Fixa as diretrizes e bases para o ensino de $1^{\underline{0}}$ e $2^{\underline{o}}$ graus e dá outras providências. Diário Oficial da União, Brasília, DF, 12 ago. 1971.

Constituição (1988). Constituição da República Federativa do Brasil. Brasília, DF: Senado Federal, 1988.

Acordo Nacional de Educação para Todos. Brasília, DF: Ministério da Educação, 1994.

Emenda Constitucional no 14, de 12 de setembro de 1996. Modifica os arts. 34, 208, 211 e 212 da Constituição Federal e dá nova redação ao art. 60 do Ato das Disposições constitucionais Transitórias. Diário Oficial da União, Brasília, DF, 13 set. 1996a.

Lei $\mathrm{n}^{\mathrm{0}}$ 9.394, de 20 de dezembro de 1996. Estabelece as diretrizes e bases da educação nacional. Diário Oficial da União, Brasília, DF, 23 dez. 1996b.

. Emenda Constitucional nº 53, de 19 de dezembro de 2006. Dá nova redação aos arts. 7ํㅜ 23, 30, 206, 208, 211 e 212 da Constituição Federal e ao art. 60 do Ato das Disposições Constitucionais Transitórias. Diário Oficial da União, Brasília, DF, 9 mar. 2006.

Lei no 11.494, de 20 de junho de 2007. Regulamenta o Fundo de Manutenção e Desenvolvimento da Educação Básica e de Valorização dos Profissionais da Educação - FUNDEB, de que trata o art. 60 do Ato das Disposições Constitucionais Transitórias; altera a Lei n⿳ำ 10.195, de 14 de fevereiro de 2001; revoga dispositivos das Leis $\mathrm{n}^{\text {os }}$ 9.424, de 24 de dezembro de 1996, 10.880, de 9 de junho de 2004, e 10.845, de 5 de março de 2004; e dá outras providências. Diário Oficial da União, Brasília, DF, 21 jun. 2007.

Lei no 11.738, de 16 de julho de 2008. Regulamenta a alínea "e" do inciso III do caput do art. 60 do Ato das Disposições Constitucionais Transitórias, para instituir o piso salarial profissional nacional para os profissionais do magistério público da educação básica. Diário Oficial da União, Brasília, DF, 17 jul. 2008.

Emenda Constitucional n⿳ำ 59, de 11 de novembro de 2009. Acrescenta $\S 3^{\circ}$ ao art. 76 do Ato das Disposições Constitucionais Transitórias para reduzir, anualmente, a partir do exercício de 2009, o percentual da Desvinculação das Receitas da União incidente sobre os recursos destinados à manutenção e desenvolvimento do ensino de que trata o art. 212 da Constituição Federal, dá nova redação aos incisos I e VII do art. 208, de forma a prever a obrigatoriedade do ensino de quatro 
a dezessete anos e ampliar a abrangência dos programas suplementares para todas as etapas da educação básica, e dá nova redação ao $\S 4^{\circ}$ do art. 211 e ao $\S 3^{\circ}$ do art. 212 e ao caput do art. 214, com a inserção neste dispositivo de inciso VI. Diário Oficial da União, Brasília, DF, 12 nov. 2009.

MONLEVADE, João A. C. O Fundef e seus pecados capitais. Brasília, DF: Idéa, 1998.

. Valorização salarial dos professores da educação básica: o papel do piso salarial nacional. 2000. Tese (Doutorado) - Faculdade de Educação, Universidade Estadual de Campinas, Campinas, 2000.

Para entender o Fundeb. Brasília, DF: Idéa, 2007.

VIEIRA, Juçara M. D. Piso salarial para os educadores brasileiros: quem toma partido? 2012. Tese (Doutorado) - Faculdade de Educação, Universidade de Brasília, Brasília, DF, 2012. 


\section{Pay and professionals in $\mathrm{EB}^{*}$ Building the yes and the how}

ABSTRACT: The article deals with the salary of professionals and the mechanism of "Cost-StudentQuality" (CAQ), both present in our laws, especially in the National Education Plan (PNE), hard-approved in 2014, and talks of the capacity to finance public education by the Brazilian state.

Keywords: Professional salary floor. Cost-student-quality (CAQ). Financing of education.

* Basic Education

\section{Bien rémunéner les professionnels de $\mathbf{l}^{\prime} \mathrm{EB}^{*}$ Comment le faire effectivement}

RÉSUMÉ: L'article traite du revenu minimum des professionnels et du mécanisme du“Coût-Eléve-Qualité" (CAQ), tous deux présents dans nos lois, spécialement dans le Plan National de l'Education (PNE), approuvés avec difficulté en 2014, et discute la capacité de financement de l'enseignement public par l'Etat Brésilien.

Mots-clés: Revenu Minimum Professionnel. Coût-ELéve-Qualité (CAQ). Financement de l'enseignement.

*Éducation Basique

\section{Pagar bien a los profesionales de la EB* Construyendo el sí y el cómo}

RESUMEN: El artículo trata del mínimo salarial de los profesionales y del mecanismo del "coste alumno/calidad" (CAC), ambos presentes en las leyes brasileñas, especialmente en el Plan Nacional de Educación (PNE), a duras penas aprobado en 2014, y habla sobre la capacidad de financiación de la enseñanza pública por parte del Estado brasileño.

Palabras clave: Mínimo salarial profesional. Coste alumno/calidad. Financiación de la enseñanza.

* Educación Básica 